\title{
Taking Private Labels Upmarket: \\ Empirical Generalizations on Category Drivers of Premium \\ Private Label Introductions
}

\author{
Anne ter Braak \\ Inge Geyskens \\ Marnik G. Dekimpe
}

January 2014

Forthcoming: Journal of Retailing

Anne ter Braak is Assistant Professor of Marketing at KU Leuven, Naamsestraat 69, 3000 Leuven, Belgium. Tel: +32-16-326 903. Fax: +32-16-326 732. E-mail:

anne.terbraak@econ.kuleuven.be. Inge Geyskens is Professor of Marketing at Tilburg University, Warandelaan 2, 5000 LE Tilburg, the Netherlands. Tel: +31-13-466 8083. E-mail:

I.Geyskens@uvt.nl. Marnik G. Dekimpe is Research Professor of Marketing at Tilburg University, Warandelaan 2, 5000 LE Tilburg, the Netherlands, and Professor of Marketing at KU Leuven, Belgium. Tel: +31-13-466 3423. E-mail: M.G.Dekimpe@uvt.nl. 


\title{
Taking Private Labels Upmarket: \\ Empirical Generalizations on Category Drivers of Premium \\ Private Label Introductions
}

\begin{abstract}
Premium private labels (PLs) are considered one of the hottest trends in grocery retailing. Still, retailers do not feel the need to introduce premium PLs in every category. Generalizing across approximately 150 categories for six retailers from two countries that already carry premium PLs for several years, the authors find that retailers are more likely to introduce premium PLs in categories with a higher industry PL share, and with a more proliferated assortment in terms of standard PLs. However, retailers are also aware of the risk of creating PL fatigue at high levels of standard PL proliferation. Further, premium PLs are more likely to be introduced in categories with more frequent price promotions, a longer interpurchase time, a higher need for variety, and higher functional, but lower social, risk. In addition, retailers consider category growth and the prevailing practice of their country's premium-PL pioneer when deciding in which categories to also introduce a premium PL. Finally, when NBs spend a smaller amount on advertising and NB proliferation is moderate, premium PL introductions are more likely. Importantly, while some of the earlier empirical generalizations on factors conducive to a standard PL entry still hold for a premium PL entry, new variables need to be considered as well, while other insights need to be updated to better reflect the new reality of higher-quality/higher-price premium PL introductions.
\end{abstract}

Keywords: grocery retailing, private labels, premium quality tier, empirical generalizations. 


\section{Introduction}

Private labels (PLs) have witnessed considerable growth around the world. The standard PL variant is by now present in almost every consumer-packaged-goods (CPG) category (de Jong 2011; IRI 2009). Still, many grocery retailers wish to expand their PL offerings even further. As a result, they increasingly adopt a multi-tiered portfolio in order to reach a wider consumer base, and offer standard, economy, as well as premium PLs (Martos-Partal and González-Benito 2011; Palmeira and Thomas 2011).

Economy PLs were primarily introduced to fight hard discounters, and are no-frills, bottomof-the-market PLs (Dekimpe et al. 2011). However, they typically have lower margins, especially in absolute terms (ter Braak, Dekimpe, and Geyskens 2013). As they have been found to cannibalize the retailer's higher-margin standard PLs (Geyskens, Gielens, and Gijsbrechts 2010), their contribution to the retailer's overall category performance has been questioned. More recently, premium PLs have emerged, which are called the hottest trend in PL retailing (Kumar and Steenkamp 2007, p. 41), and referred to as many retailers' "Holy Grail” (Pauwels and Srinivasan 2009, p. 279). Premium PLs are positioned at the top end of the market, and their unique features in terms of taste, origin, and/or ingredients enable retailers to compete with the highest-quality national brands (NBs) (Bazoche, Giraud-Héraud, and Soler 2005; Geyskens et al. 2010). Notable examples include Loblaw's President's Choice in the U.S., FairPrice Gold by NTUC FairPrice in Singapore, and Tesco's Finest in the U.K. The latter has recently been estimated to be worth about \$2.26 billion in annual sales (Store Brand Decisions 2013).

Of all PL tiers, the market shares of premium PLs have been growing the fastest (Dobson 
and Chakraborty 2009), ${ }^{1}$ even though retailers refrain from offering them in too many categories (Pierce, Ryan, and Berlinksi 2002; Sethuraman and Raju 2012). As premium PLs directly compete with the highest-quality NBs in the category, the retailer's relationship with leading NB manufacturers may be affected. Since leading NBs continue to play an important role in signposting a category (IGD 2006), retailers remain selective in picking their battles with topquality NBs (Kumar and Steenkamp 2007).

Following an extensive review of the PL literature, Sethuraman (2009, p. 773) emphasized the need for more empirical research on "conditions conducive for premium private labels." To that extent, we analyze in which categories several retailers from two different countries that are widely seen to be at the forefront of new PL developments (Belgium and the Netherlands; de Jong 2011) introduce premium PLs. By focusing on communalities in these retailers' practices, we formalize the "combined industry wisdom" in the domain. By considering multiple retailers, our insights become more generalizable, and less sensitive to the idiosyncratic features of a single organization's decision process.

Managerially, our study helps retailers identify appropriate categories for premium PL introductions, and reduce the risk of having to withdraw them at a later stage (cf. Raju, Sethuraman, and Dhar 1995). When faced with novel situations, retailers (and managers in general; see, e.g., Anderson 1988 and Geletkanycz and Hambrick 1997) often turn to prevailing practices in their industry to learn which decisions are good, or even best (Gielens and Dekimpe 2007). As more and more retailers prepare to add a premium line to their PL portfolio, these insights have clear managerial relevance. Likewise, NB manufacturers can infer in which categories they are most likely to face this new competitor, and learn what preemptive strategies

\footnotetext{
${ }^{1}$ In Germany, for example, the premium PL segment already captures $13 \%$ of the CPG market (Wildner 2013), up from $8.8 \%$ in 2005, while the Italian premium PL market experienced a growth rate of $22.3 \%$ in 2010, reaching a level of 5\% of the total CPG market (SymphonyIRI 2011).
} 
to adopt to deter premium PL introductions in their category. The importance of this issue is also reflected in the Harvard Business School case on the PL portfolio of retailer H.E.B. (Rangan and Bell 2003).

Substantively, we investigate to what extent earlier empirical generalizations (see, e.g., Sethuraman 2009; Sethuraman and Gielens 2013) on the category drivers of standard PL introductions still hold, or whether they should be adjusted when dealing with the new reality of higher-quality/higher-price premium PL introductions. In addition, we consider the impact of a new set of potential drivers, which were not yet relevant in a standard PL setting, but which have come to the fore in a multi-tiered PL landscape. As such, we add to the empirical knowledge base on an important recent trend in retailing that is clearly in need of more empirical research, and (in line with the recommendations of Barwise 1995) we identify potential boundary conditions to earlier empirical generalizations.

\section{Theoretical background and hypotheses}

Several studies have looked at the drivers of standard PL introductions (see, e.g., Raju et al. 1995; Sayman and Raju 2004; Scott-Morton and Zettelmeyer 2004) and standard PL success (see, e.g., Dhar and Hoch 1997; Hoch and Banerji 1993; Steenkamp and Geyskens 2014). Recent reviews of this literature include Sethuraman (2009) and Sethuraman and Gielens (2013), among others. It is unclear, however, to what extent empirical generalizations that have been derived from that literature still apply in the context of premium PL introductions, for two reasons.

Foremost, the competitive setting has changed. When deciding whether or not to introduce a standard PL in a category, NBs were the only incumbents retailers had to consider. However, 
standard PLs are currently offered in almost all categories (IRI 2009), and retailers deciding on the addition of a premium PL should now also take their standard PL offering in that category into account. This leads to a new set of variables - which were not yet relevant in prior standard PL studies - that should be considered when studying premium PL introductions.

Second, the positioning of premium PLs is very different from the positioning of standard PLs. While standard PLs tend to imitate mainstream-quality manufacturer brands (Geyskens et al. 2010), they are typically sold at a price 20 to $30 \%$ below that of the NBs they are competing with (Steenkamp, van Heerde, and Geyskens 2010). Premium PLs, in contrast, are positioned at the top end of the market, and deliver quality similar to or higher than premium-quality NBs (Geyskens et al. 2010). Also their price is very similar to (and sometimes even higher) than the price of the premium-quality NBs. Because of this, quality becomes much less of a differentiator for NBs vis-à-vis premium PLs than vis-à-vis standard PL variants (Sethuraman and Raju 2012). Similarly, while standard PLs have often been viewed as products catering mostly to the pricesensitive (switcher) segment, this may be less the case for premium variants: premium PLs are more intended to contribute to a distinct category- and store-quality image (Thain and Bradley 2012). Given these considerations, the role of price, quality, and imagery-related variables may have to be reconsidered for premium PLs. Although such variables have already been studied in the literature on standard PLs, unlike the set mentioned before, their effect may be different for premium PLs.

In what follows, we offer expectations as to how these two sets of variables affect a retailer's propensity to introduce a premium PL in a category next to his standard PL. Figure 1 summarizes our conceptual framework.

--- Insert Figure 1 about here --- 


\section{Expectations related to the extant PL competitive setting}

Retailers' inclination to introduce a premium PL is likely to depend on the strength of the standard PL incumbents in the category. To that extent, we study (i) the industry PL share in the category, (ii) the retailer's standard PL share in the category, and (iii) the retailer's standard PL assortment proliferation.

Industry PL share

The industry PL share, i.e., the PL share in a product category across all retailers in a country, signals the intrinsic appeal of PL products to consumers (Kumar and Steenkamp 2007). We expect that retailers are more inclined to introduce a premium PL in categories in which industry PL share - a measure of the relative strength of PLs in a category - is high.

H1: Higher industry PL share in a category increases a retailer's propensity to introduce a premium PL in that category.

\section{Standard PL share}

In categories in which a retailer already has a high standard PL share, his PL expertise lies in the offering of functional, price-based products (Kumar and Steenkamp 2007). Consumers are more likely to be skeptical of extensions that deviate considerably from this practice (Aaker and Keller 1990), as with quality-focused premium PL extensions. Moreover, the resulting quality variation across the different tiers may dilute the signaling value of the PL brand (Szymanowski and Gijsbrechts 2012). In addition, when standard PL share in a category is high, the likelihood of cannibalizing the incumbent PLs (as opposed to NBs) increases (Geyskens et al. 2010). This lowers the retailer's profits for the standard PL.

In sum, it is more difficult to introduce premium PL SKUs in categories in which the 
standard PL of the retailer is stronger. Combined with the more pronounced cannibalization threat, we postulate that a retailer is less inclined to introduce a premium PL in categories where his standard PL share is higher.

H2: Higher standard PL share in a category decreases a retailer's propensity to introduce a premium PL in that category.

\section{Standard PL proliferation}

Standard PL SKU proliferation signals the retailer's commitment to his PL program (Dhar and Hoch 1997), which may facilitate further investments in a premium PL. However, as retailers keep on extending their PL portfolio, countervailing forces may come at work, and may become especially strong at very high levels of PL SKU proliferation. First, adding too many PL variants may cause PL fatigue with consumers (Dobson and Chakraborty 2009). Second, when standard PL SKU proliferation is high, a retailer's resources may already be stretched, which could deter the investments needed for the premium PL (Dekimpe et al. 2011).

The aforementioned, opposing, points of view can be reconciled by positing an inverted Ushaped effect for the extent of standard PL proliferation on the likelihood of a premium PL introduction in the category.

H3: The effect of standard PL SKU proliferation in a category on a retailer's propensity to introduce a premium PL in that category follows an inverted U-shape.

\section{Expectations related to the positioning of premium PLs}

In what follows, we distinguish between expectations related to the price positioning of premium PLs, and expectations related to the quality and imagery positioning of premium PLs. 
Expectations related to the price positioning of premium PLs

NB price premium. The ability of NBs to charge a higher price than standard PLs varies substantially across categories (Steenkamp et al. 2010). The higher the price premium, the more NBs are situated in a very different price bracket than the standard PLs. This would also be the case for premium PLs, which are (as indicated before) priced similarly, or even higher than, the leading NBs. Because of the resulting price differentiation, the cannibalisation threat - a key concern to retailers when considering to introduce a premium PL variant in a given category is reduced.

Moreover, wholesale prices are known to be higher for premium PLs than for their standard counterpart (ter Braak et al. 2013), due to the higher standards and consistent quality requirements that retailers impose on their premium PL suppliers (Sayman and Raju 2007). Because of this, a sufficiently large price premium is called for to ensure the larger profit margin premium PLs aim to achieve (Sethuraman and Raju 2012). This is more difficult to realize if other products with a similar quality positioning (the NBs) go for a smaller price premium. Hence, we expect that a retailer's propensity to introduce a premium PL in a category is positively affected by the NB price premium in the category.

H4: A higher NB price premium in a category increases a retailer's propensity to introduce a premium PL in that category.

NB price-promotion intensity. Standard PLs have been shown to be more successful in categories with more frequent and deeper NB promotions (Kumar and Steenkamp 2007). In such an environment, consumer acceptance of the (higher) regular NB prices is reduced, making consumers more price (promotion) oriented buyers (Mela, Gupta, and Lehmann 1997), who may eventually switch to the cheaper standard PL. However, others have found standard PLs to 
perform worse in categories with more frequent and deeper NB promotions, since standard PLs lose their comparative price advantage in these categories (Dhar and Hoch 1997; Sethuraman 1992). When NBs compete intensely on price, little room is left for the PL to be profitable. In such a setting, the retailer may be better off exploiting the competition among the NBs without offering a standard PL (Raju et al. 1995).

Premium PLs have a very different price positioning than the standard variants. Because of this, both aforementioned arguments may now work in the same direction to discourage their introduction. Compared to the standard PL, premium PLs are at a clear disadvantage in an environment where consumers have been trained to focus more on the price attribute than on the product's intrinsic quality (Nijs et al. 2001). Compared to the NBs, with which they share a highquality focus, they are at a competitive disadvantage when the latter are heavily promoted. We therefore hypothesize:

H5: Higher NB price-promotion intensity in a category, in terms of (a) deal frequency and (b) deal depth, decreases a retailer's propensity to introduce a premium PL in that category. Interpurchase cycle. Since premium PLs are higher-priced, retailers may avoid introducing them in categories with shorter interpurchase times. Indeed, if the average time between purchases is low, consumers have more opportunities to compare and learn about prices (Ailawadi and Harlam 2004), which increases their price sensitivity (Ailawadi, Lehmann, and Neslin 2003). Thus, we expect that retailers are less likely to introduce premium PLs in categories with a shorter interpurchase cycle for consumers.

H6: Shorter interpurchase cycle in a category decreases a retailer's propensity to introduce a premium PL in that category.

Need for variety. Consumers' need for variety refers to their desire for a wide assortment of 
products to choose from in a given category. Consumers may seek variety in one product category but not in another (van Trijp, Hoyer, and Inman 1996). Consumers high on need for variety are particularly receptive to innovative product offerings to satisfy their variety seeking needs (Mittelstaedt et al. 1976), and are less sensitive to the price of these products (Baumgartner and Steenkamp 1996). We therefore expect that a retailer is more inclined to introduce a premium PL in categories where the need for variety is higher.

H7: Higher need for variety in a category increases a retailer's propensity to introduce a premium PL in that category.

\section{Expectations related to the quality and imagery positioning of premium PLs}

Perceived risk. Purchasing a NB is a risk-reduction strategy that consumers employ in categories that are characterized by high perceived risk (Erdem, Zhao, and Valenzuela 2004). We consider two sources of category-specific risk commonly distinguished in the literature functional risk and social risk. Functional risk deals with the uncertainty about the quality of the product, while social risk deals with the extent to which purchases in the category are closely tied to the consumer's ego and self-image (Laurent and Kapferer 1985). In the first instance, an erroneous purchase leads to disappointing functional performance, while in the second case it leads to feelings of frustration and embarrassment.

Steenkamp and Geyskens (2014) have found that standard PL share is lower in categories in which consumers perceive a lot of functional risk associated with the purchase - since NBs are still widely perceived to be of better quality than standard PLs - and in categories in which consumers perceive a lot of social risk - since NBs excel on brand imagery compared to standard PLs.

In contrast to standard PLs, premium PLs are squarely positioned at the top end of the quality 
spectrum. Consequently, we argue that retailers will be more inclined to introduce a premium PL in categories characterized by higher functional risk. In contrast, we do not expect a similar effect for social risk. As the most visible marketing symbol, brands are imbued with meaning. They allow consumers to identify with the values instilled in the brand, and help them express who they are. Consequently, brands "have significance that goes beyond their [...] utilitarian character" (Aaker, Benet-Martinez, and Garolera 2001, p. 493). Although premiums PLs are starting to acquire intangible meaning too, NBs still hold a clear edge in developing a personalized social emotional bond with the consumer, as they are more narrowly focused on specific categories (Kumar and Steenkamp 2007). In contrast, "private label imagery is intimately tied to the store's imagery, which by definition will always have to be very broad and bland in comparison" (Thain and Bradley 2012, p. 157). This leaves less scope for premium PLs

to develop emotional (image) utility in a specific category. Therefore, we expect that a retailer is less inclined to introduce a premium PL in categories where social risk is higher.

H8: Higher functional risk in a category increases a retailer's propensity to introduce a premium PL in that category.

H9: Lower social risk in a category increases a retailer's propensity to introduce a premium PL in that category.

\section{Expectations that generalize from standard PLs to premium PLs}

While our focus is on the drivers of PL entry that do not necessarily generalize from the standard PL to the premium PL context, we control for the impact of variables that we do expect to generalize. We do so to arrive at more precise estimates of the effects of the non-generalizable 
drivers (Greene 2000). Specifically, we control for two blocks of variables, viz. (i) the category's potential, and (ii) the extant NB setting, for which we expect that the collective wisdom on standard PL entry/success also applies to the introduction/success of premium PLs. Based on the literature reviewed in, among others, Kumar and Steenkamp (2007), Sethuraman (2009), Sethuraman and Gielens (2013), and Steenkamp and Geyskens (2014), we briefly motivate generalized expectations as to the likely effect of each factor.

Empirical generalizations related to the category's potential

Some categories are more attractive than others for new products in general (Robinson 1988), and for new standard and premium PL products in particular. We consider the category's (i) size, (ii) growth, (iii) penetration, and (iv) pioneer signaling behavior.

Category size. Even a small share of a large category may generate sufficient revenues to cover the overhead of a new product introduction (Hoch and Banerji 1993). We therefore expect that larger category size will increase a retailer's propensity to introduce a premium PL in the category.

Category growth. Category growth signals future market potential, and has been shown to positively affect both retail acceptance of new products (Rao and McLaughlin 1989) and newproduct performance (Henard and Szymanski 2001). As such, we also expect that higher category growth increases a retailer's propensity to introduce a premium PL in that category.

Category penetration. The limited importance to the retailer of low-penetration categories may not justify the time and effort necessary to develop a PL operation in those categories (Steenkamp and Geyskens 2014). We thus expect that a retailer is more likely to introduce a premium PL in categories with higher penetration.

Pioneer signaling behavior. Faced with considerable uncertainty given the recency of the 
premium PL phenomenon, retailers may look at the prevailing practices of other players in the industry to guide their own decisions (Koçak and Özcan 2013). Retailers attach more weight to the actions of some competitors than of others (Gielens and Dekimpe 2007). Specifically, they may believe that the premium PL pioneer has superior information, which allows him to identify interesting market opportunities better or more quickly (Carow, Heron, and Saxton 2004). Therefore, if the pioneer has introduced a premium PL in the category, a positive effect is expected on the propensity of other retailers to also do so.

\section{Empirical generalizations related to the extant $N B$ competitive setting}

Retailers' inclination to introduce premium PLs is likely to depend on the strength of the NB incumbents in the category. To that extent, we study a category's (i) NB concentration, (ii) NB proliferation, and (iii) NB advertising.

NB concentration. When NB concentration is higher, brands are more powerful. Increased brand power translates in wider distribution and more shelf space (Reibstein and Farris 1995). Moreover, retailers may find it more difficult to find a supplier for their PLs in markets with higher NB concentration (Scott-Morton and Zettelmeyer 2004). In contrast, markets with low NB concentration are fragmented and highly competitive. Such markets are easier to enter by PLs. We thus expect that a retailer is more likely to introduce a premium PL in categories with lower NB concentration

NB proliferation. Raju et al. (1995) find that PLs are more likely to be introduced in categories with a higher NB proliferation. As this level increases, a retailer's interest in offering a more diverse PL assortment in that category increases. However, if NB proliferation is very high, Dhar and Hoch (1997) have shown that the market becomes cluttered, resulting in a pure crowding out effect: a newly introduced PL will not stand out anymore. Moreover, highly 
proliferated assortments act as a deterrent to entry because market share in the category is already carved up into many pieces (Hoch and Banerji 1993; Sethuraman 1992), leaving a smaller share of the pie for the new entrant. The aforementioned points of view can be reconciled by positing an inverted U-shaped effect for the extent of NB SKU proliferation on the likelihood of a premium PL introduction in the category.

NB advertising. Advertising support for NBs significantly contributes to their brand equity (Sriram, Balachander, and Kalwani 2007). Advertising can positively affect brand equity through the creation of favorable associations and experiences, causing an improvement in perceived quality (Keller 1998). Sethuraman and Gielens (2013) conclude that heavy NB advertising is a significant barrier to standard PL success (see also Dhar and Hoch 1997; Sethuraman 1992). We expect that NB advertising also keeps premium PLs at bay by emphasizing brand image and associations, over and above objective quality advantages, thereby differentiating NBs from their premium PL competitors (Boulding, Lee, and Staelin 1994). Thus, we expect that higher NB advertising decreases the likelihood that a retailer introduces premium PLs in the category.

\section{Research setting and measures}

\section{Setting}

Western Europe is by far the most developed PL region in the world (PlanetRetail 2008a). Since Europe is the cradle of premium PLs - in contrast to the U.S., where retailers have only recently begun to consider the opportunities of premium PLs (IRI 2009) - we study several European retailers that already carry a premium PL line for some years. First, we study four of the largest retailers in the Netherlands, which is within Europe one of the front-runners in terms 
of new PL developments (de Jong 2007; IRI 2009): ${ }^{2}$ (i) Albert Heijn, the flagship of Royal Ahold, one of the world's largest grocery retailers, (ii) Jumbo, (iii) Plus, and (iv) Super de Boer. Because of their pioneering role, several of these retailers have featured in previous PL studies, such as Ailawadi, Pauwels, and Steenkamp (2008) and Steenkamp and Dekimpe (1997). We also examine two leading Belgian retailers: (i) Carrefour (part of the French supermarket concern) and (ii) Delhaize (the parent company of U.S.-based Food Lion).

\section{Data}

Our data cover the period 2002-2012 for the Netherlands, and 2005-2012 for Belgium. As we need two years prior to a premium PL introduction to operationalize one of our covariates (viz., category growth prior to the potential introduction), while we also consider the performance of the introduced premium PL in the year following its introduction (as we will discuss later), we consider all introductions between 2004 and 2011 for Albert Heijn (the pioneer in the Netherlands), and between 2007 and 2011 for Carrefour (the pioneer in Belgium) and Delhaize. For the other retailers, we consider all introductions from the start of their premium PL program onwards (2005 for Super de Boer, 2006 for Plus, and 2007 for Jumbo) up to the end of $2011{ }^{3}$ We consider all food and beverage categories in which the retailers consistently carried a standard PL in addition to their NB offering, and in which they had not introduced a premium PL before (i.e., categories that were "still at risk" at that time). Hence, we model the decision in which categories to introduce a premium PL (once the decision to offer a premium PL line has

\footnotetext{
${ }^{2}$ To illustrate, by the end of 2010, one in four households already bought premium PLs in the Netherlands (Distrifood 2010).

${ }^{3}$ For Super de Boer, we considered introductions up to the end of 2009 , as the chain was acquired by another chain in 2010.
} 
been made), and not the decision whether and when to start with the premium PL line itself. The latter may reflect broader strategic considerations, such as the higher overall margin that can be realized through premium PL offerings (ter Braak et al. 2013) or the need to further differentiate the chain from its competitors (Sethuraman and Raju 2012) and build a loyal segment (Sethuraman 2009). ${ }^{4}$ All covariates in our model, except for four survey-based measures, are operationalized in a time-varying way one year prior to the (potential) premium PL introduction.

Premium PL introduction. We measure "premium PL introduction" (PREMIUM) as a binary variable that is coded 1 if the retailer introduces a premium PL in the category in the respective year, and 0 otherwise. By the end of the observation period (2009 for Super de Boer, 2011 for the five other retailers), Albert Heijn, Jumbo, Plus, Super de Boer, Carrefour, and Delhaize had introduced a premium PL in 53\%, 37\%, 41\%, 23\%, 46\%, and 13\% of the categories "at risk" at the beginning of the observation window (the latter are reported in the third row of Table 1). PL SKUs were classified into one of three tiers on the basis of their brand name; the various tiers are typically tied to the banner's umbrella brand name, while carrying a different sub-brand name. The premium lines are offered under the names 'AH Excellent' (Albert Heijn), 'Jumbo Exclusief’, 'Plus Appétit', 'Super de Boer Superieur', 'Carrefour Selection', and 'Delhaize Taste of Inspirations'.

Industry PL share. Industry PL share (INDPLSHARE) is operationalized as the timevarying ratio of national category PL volume sales compared to total national category volume sales (cf. Hoch and Banerji 1993). Average industry PL share equals 53\% in the Netherlands and $55 \%$ in Belgium.

Standard PL share. Standard PL share (STPLSHARE) is operationalized as the time-varying

\footnotetext{
${ }^{4}$ This store-loyalty argument was, for example, one of the main drivers behind the decision of the German Rewe Group to introduce its premium PL line "Rewe Feine Welt" (press release of August 13, 2009).
} 
ratio of category volume sales of a retailer's standard PLs compared to the total category volume sales at the retailer (cf. Hoch and Banerji 1993). Average category standard PL share ranges between $32 \%$ and $48 \%$ for the six retailers in our sample.

Standard PL proliferation. Standard PL proliferation is captured by the number of unique standard PL SKUs (PLSKUS) offered by the retailer in the category during a given year (cf. Gielens 2012). On average, across the six retailers, between 10 and 16 standard PL SKUs are carried per category. Given that we include a squared term of PL SKU proliferation, it is meancentered to facilitate interpretation (Cohen et al. 2003).

NB price premium. The NB price premium (NBPREMIUM) reflects the ratio of the retailer's average non-promotional NB price of the leading NB to the retailer's average nonpromotional standard PL price (in equivalent units) in the category in a given year (cf. Deleersnyder et al. 2007). On average, across all category-year observations, NBs are priced $28 \%$ higher than standard PLs.

NB price-promotion intensity. A category's deal frequency (NBDEALFREQ) is measured as the percentage of all NB volume sales in a category at the retailer made on a price promotion during a given year. A category's deal depth (NBDEALDEPTH) is operationalized as the average percentage discount when a NB purchase in the category is made on a price promotion during a given year at the retailer (Ailawadi and Harlam 2004). A price promotion is identified when the price of the NB is at least $5 \%$ below its grand-average price level (see, e.g., Rao, Arjunji, and Murthi 1995 for similar practice). Across the six retailers, between $14 \%$ and $21 \%$ of all NB sales in a category are bought on a price promotion. The average price discount across all promotional purchases in a category is $18 \%$.

Interpurchase cycle. Following Fader and Lodish (1990), we operationalize interpurchase 
cycle (PURCYCLE) as the average interpurchase time (in days) for households that make at least two purchases in the category with the retailer during a given year.

Need for variety, functional risk, and social risk. Need for variety (NEEDVAR), functional risk (FUNCRISK), and social risk (SOCRISK) are measured using 1 item, 2 items, and 3 items, respectively, based on a 5-point Likert scale, as perceived by Dutch and Belgian consumers (for a similar practice, see Steenkamp et al. 2004 and Steenkamp and Geyskens 2014). Unlike the previous covariates, these variables were not time-varying (i.e., the survey was undertaken at one point in time). Details on the specific items used are provided in Web Appendix A.

Category size. Following Hoch and Banerji (1993), we measure category size (CATSIZE) as the total category sales value (in euros) at the retailer in a given year.

Category growth. We operationalize category growth (CATGROWTH) as the yearly rate of change in category value sales at the retailer, i.e., the ratio of value sales in the year before we measure a (potential) premium PL introduction relative to the preceding year. While some categories are shrinking (growth $<1$ ), most have seen a positive growth (median $=1.04$ ).

Category penetration. Following Fader and Lodish (1990), we operationalize category penetration (CATPEN) as the percentage of all households that make at least one purchase in the product category with the retailer during a given year.

Pioneer signaling behavior. Albert Heijn was the first retailer to introduce a premium PL in the Dutch market, while Carrefour was the first retailer to do so in the Belgian market. Hence, for the four other retailers, we include a dummy variable for the premium PL presence of the pioneer (PIONEER) in a given category in the year prior to a (potential) premium PL introduction.

NB concentration. NB concentration (NBCONC) is measured as the sum of the squared 
volume market shares of the top three NBs in the category at the retailer in a given year.

NB proliferation. NB proliferation is measured by the number of unique NB SKUs (NBSKUS) offered in a category at a retailer in a given year (cf. Gielens 2012). On average, 41 NB SKUs are carried per category. Given that we include a squared term of NB SKU proliferation, it is mean-centered to facilitate interpretation (Cohen et al. 2003).

$N B$ advertising. As the actual spending figures were not available to us, we include perceived NB advertising intensity (NBADV) in a category as a proxy, measured on a 5-point Likert scale (for a similar practice, see Steenkamp et al. 2010 and ter Braak et al. 2013). The information on advertising intensity was obtained in the same survey among Dutch and Belgian consumers as the need for variety, functional risk, and social risk measures, and is therefore not time-varying (for details, see Web Appendix A).

Control variables. Apart from these focal constructs, we also control for the presence of an economy PL in the category (ECONOMY). Many European retailers have introduced an economy PL tier as part of their multi-tier PL portfolio to address the needs of more price conscious consumers (Dekimpe et al. 2011). We include a time-varying dummy that is coded 1 if the retailer carries an economy PL in the category in a given year, and 0 otherwise. Albert Heijn, Jumbo, Super de Boer, Carrefour, and Delhaize carried an economy PL line, in a maximum of 91, $29,53,101$, and 102 categories across the years of our data, respectively.

Table 1 provides summary information on the premium PL introductions and category characteristics for each of the six retailers in our sample. In the Netherlands, Albert Heijn has the most extensive PL assortment. It introduced a premium PL in 53\% of the categories and has a $48 \%$ standard PL share. On average, Albert Heijn carries 12 standard PL SKUs in a category. ${ }^{5}$ Jumbo,

\footnotetext{
${ }^{5}$ For some categories, however, this proliferation is much more extensive, as will be discussed in more detail in our results section.
} 
in contrast, carries "only" 11 standard PL SKUs in a category, but carries a more extensive NB assortment. As is apparent from the price-promotion intensity numbers, Albert Heijn is a clear Hi-Lo oriented retailer (average deal frequency $=21 \%$, average deal depth $=19 \%$ ), whereas Jumbo is more of an EDLP retailer. It sells less on deal (average deal frequency $=14 \%$ ), and NB discounts are less deep (average deal depth $=15 \%$ ). Plus and Super de Boer are positioned in between (average deal frequency $=21 \%$ and $20 \%$; average deal depth $=16 \%$ and $18 \%$ ). In Belgium, Carrefour carries the most extensive premium PL assortment, with a premium PL in 46\% of its categories. In contrast, Delhaize offers the most extensive standard PL assortment. Although Delhaize sells less on promotion (average deal frequency $=17 \%$ ) than Carrefour (average deal frequency $=20 \%)$, NB discounts are equally deep (average deal depth Delhaize $=$ $21 \%$; average deal depth Carrefour $=20 \%$ ).

--- Insert Table 1 about here ---

\section{Model}

To model not only the decision whether or not to introduce a premium PL in a given category, but to also capture the timing of that event, we fitted a discrete-time hazard model to the data. ${ }^{6}$ To that extent, we transformed (as described in Singer and Willett 2003, Chapter 11) each retailer's category-level data set into a category-year data set, ${ }^{7}$ to which we applied a standard logistic regression analysis. Categories that witnessed, for example, a premium PL introduction in the third year, contribute three observations to the category-year data set.

\footnotetext{
${ }^{6}$ Recent marketing applications of discrete-time hazard models include Woltman Elpers, Wedel, and Pieters (2003) and Alexander, Lynch, and Wang (2008), among others.

${ }^{7}$ For example, for Albert Heijn, the information on their 179 categories gave rise to 976 category-year observations (see Table 1).
} 
Censored observations (i.e., which did not witness such an introduction in our observation window) contribute an observation each year that they were "at risk" (i.e., when a premium PL could have been introduced). Equation (1) depicts the logistic model used:

$$
\begin{aligned}
& \operatorname{Pr}\left(\text { PREMIUM }_{\mathrm{ct}}=1\right)=\Lambda\left[\beta_{0 \mathrm{t}}+\beta_{1} \text { INDPLSHARE }_{\mathrm{ct}-1}+\beta_{2} \text { STPLSHARE }_{\mathrm{ct}-1}\right. \\
& \left.+\beta_{3} \text { PLSKUS }_{\mathrm{ct}-1}+\beta_{4} \text { PLSKUS }_{\mathrm{ct}-1}\right)+\beta_{5} \text { NBPREMIUM }_{\mathrm{ct}-1}+\beta_{6} \text { NBDEALFREQ }_{\mathrm{ct}-} \\
& +\beta_{7} \text { NBDEALDEPTH }_{\mathrm{ct}-1}+\beta_{8} \text { PURCYCLE }_{\mathrm{ct}-1}+\beta_{9} \text { NEEDVAR }_{\mathrm{c}}+\beta_{10} \text { FUNCRISK }_{\mathrm{c}} \\
& +\beta_{11} \text { SOCRISK }_{\mathrm{c}}+\beta_{12} \text { CATSIZE }_{\mathrm{ct}-1}+\beta_{13} \text { CATGROWTH }_{\mathrm{ct}-1}+\beta_{14} \text { CATPEN }_{\mathrm{ct}-1} \\
& \left.+\beta_{15} \text { PIONEER }_{\mathrm{ct}-1}+\beta_{16} \text { NBCONC }_{\mathrm{ct}-1}+\beta_{17} \text { NBSKUS }_{\mathrm{ct}-1}+\beta_{18} \text { NBSKUS }_{\mathrm{ct}-1}\right) \\
& \left.+\beta_{19} \text { NBADV }_{\mathrm{c}}+\beta_{20} \text { ECONOMY }_{\mathrm{ct}-1}\right]
\end{aligned}
$$

with $\Lambda$ the CDF of the logistic distribution. The $\beta_{0 t}$ refer to the year-specific constants, and reflect the evolution of the base hazard. In some instances, no introduction was observed in a given year, which prevented the estimation of a separate intercept for that year. Following Dekimpe et al. (1998), we then grouped two consecutive years as the time-interval for the basehazard specification. Importantly, all time-varying covariates were operationalized using information from the year prior to a (potential) premium PL introduction to preclude reversecausality concerns.

To allow for the potential intercorrelation among multiple observations within broader product groups, we use a cluster-robust estimation procedure (in line with the recommendation of Mizik and Jacobson 2009, and as recently used in Cleeren, van Heerde, and Dekimpe 2013 and ter Braak et al. 2013). ${ }^{8}$ For Jumbo, we perform Firth's penalized maximum likelihood estimation (Heinze 1999) instead to correct for a quasi-complete separation of data points, given

\footnotetext{
${ }^{8}$ Eight such product groups were considered: ambient, bakery products, beverages, dairy, frozen foods, fruit and vegetables, meat and fish, and ready meals.
} 
that no premium PL introduction was observed for categories that contained an economy PL. ${ }^{9}$

We estimate this model separately for the six retailers. Given our interest in the overall effect of the category characteristics on a retailer's proneness to introduce a premium PL in a category, and this across the six retailers, we focus on the combined significance of the corresponding parameter estimates using Rosenthal's (1991) meta-analytical test of added Z's. ${ }^{10}$ As this test combines evidence across the six retailers in our sample, it allows us to derive more generalizable insights. However, meta-analysis does not pool the retailers into a single sample. As such, we do not impose any restrictions on the sign and/or magnitude of the coefficients, and therefore allow for potential differences among the retailers. The effect size of parameter $\beta$ is the weighted mean response parameter across retailers. The weight is the inverse of the estimate's standard error, normalized to one. Thus, $\beta$ can be interpreted as a reliability-weighted mean, where estimates with higher reliability (lower standard error) obtain a higher weight, similar in spirit to a hierarchical mean in a Bayesian model (see van Heerde et al. 2013 for a similar reasoning).

Across all 100+ VIF values, only three VIF statistics marginally exceed the often-used recommended cut-off-value of 10 (Cohen et al. 2003; Wooldridge 2009), suggesting that multicollinearity is not a major concern. We provide correlations between all covariates per retailer in Web Appendix B, ${ }^{11}$ which also reports (when relevant) the correlation between each covariate and its lagged value.

\footnotetext{
${ }^{9}$ Our meta-analysis results are also stable when we exclude the economy PL dummy for Jumbo and again use a cluster-robust estimation procedure.

${ }^{10}$ See, for example, Deleersnyder et al. (2009) or van Heerde et al. (2013) for recent marketing applications. A technical exposition is given in the latter's Web Appendix.

${ }^{11}$ Only two of the 950+ correlations just exceed the usual cut-off of .80 (Judge et al. 1988) (for Carrefour, the correlation between category size and NB proliferation equals .81; for Super de Boer, the correlation between category size and penetration equals .82).
} 


\section{Results}

Our model fits the data well. Because of the skewed nature of the outcome variable (with many categories without premium PL introduction), we follow Stepanova and Thomas (2002), and use a cut-off where the number of premium PL introductions predicted for a retailer in a certain year agrees with the actual number of introductions observed in the sample. This results in a classification accuracy for Albert Heijn, Jumbo, Plus, Super de Boer, Carrefour, and Delhaize for our model of $87.5 \%, 88.6 \%, 90.1 \%, 93.7 \%, 85.0 \%$, and $96.0 \%$, respectively. ${ }^{12}$ This is consistently higher than the proportional chance criterion of a random model, where the classification accuracy would equal $82.6 \%, 83.8 \%, 85.3 \%, 90.5 \%, 79.3 \%$, and $94.8 \%$, respectively. The proportional chance criterion yields a hit rate of $\alpha^{2}+(1-\alpha)^{2}$, with $\alpha$ the observed proportion of premium PL introductions at the retailer (Morrison 1969).

Given that the event of no premium PL introduction in a category is much more likely, we also look at the ability of our model to correctly predict the (less likely) event of a premium PL introduction in a category. The chance percentage $(\alpha)$ of a premium PL introduction in a category (Morrison 1969, p. 160) equals $9.6 \%, 8.9 \%, 8.0 \%, 5.0 \%, 11.7 \%$, and $2.7 \%,{ }^{13}$ whereas our model correctly classifies $35.1 \%, 35.7 \%, 37.9 \%, 37.1 \%, 36.1 \%$, and $25.0 \%$ of the observations with a premium PL introduction for Albert Heijn, Jumbo, Plus, Super de Boer, Carrefour, and Delhaize, respectively. ${ }^{14}$ Hence, our model clearly outperforms the random benchmark model on both dimensions.

\footnotetext{
12 These hit rates correspond to the fractions 854/976, 557/629, 656/728, 655/699, 523/615, and 869/905 for Albert Heijn, Jumbo, Plus, Super de Boer, Carrefour, and Delhaize, respectively.

${ }^{13}$ These percentages correspond to the following numbers from Table 1: 94/976, 56/629, 58/728, 35/699, 72/615, and 24/905 for Albert Heijn, Jumbo, Plus, Super de Boer, Carrefour, and Delhaize, respectively.

14 These hit rates correspond to the fractions 33/94, 20/56, 22/58, 13/35, 26/72, and 6/24 for Albert Heijn, Jumbo, Plus, Super de Boer, Carrefour, and Delhaize, respectively.
} 
Table 2 reports the parameter estimates. In line with our research objectives, we primarily focus on the findings that are specific to our premium PL setting, i.e., which relate to, respectively, the extant PL competitive setting and the premium PLs' unique positioning. Next, we also report to what extent prior findings from the standard PL setting generalize to the premium case.

\section{Findings specific to premium PLs: the role of the extant PL competitive setting}

For all retailers, the coefficient for industry PL share shows the expected positive sign, even though the test is significant for only two retailers. The meta-analytic method of added Z's results in a significant positive effect $(\mathrm{Z}=2.28, p<.05)$, in line with $\mathrm{H} 1$. When PLs in a category are stronger at the country-level (i.e., across all retailers), a premium PL is more likely

to be introduced in the category $(\bar{\beta}=1.03)$. However, we do not find evidence for the proposed negative effect of standard PL share in the category at the retailer-level $(\bar{\beta}=-.01 ; \mathrm{Z}=-.01$, $p>.10$ ), and therefore cannot confirm H2. Thus, a retailer's own cannibalization fears do not seem to outweigh the benefits that might come from the favorable overall reputation PLs command, across all retailers, in those categories. Furthermore, the collective evidence partly confirms H3, and shows a positive effect of standard PL proliferation, but no sign yet of an inverted-U shape (linear effect: $\bar{\beta}_{\text {lin }}=.22 ; Z=2.50, p<.01 ;$ squared effect: $\bar{\beta}_{\text {sq }}=-.01 ; Z=-.87$, $p>$.10). However, for two retailers, we do find that the effect of standard PL SKU proliferation follows an inverted U-shape (Albert Heijn linear effect: $\beta_{\text {lin }}=.44, p<.01$; squared effect: $\beta_{\mathrm{sq}}=$ $-.02, p<.01$; Delhaize linear effect: $\beta_{\text {lin }}=.35, p<.05 ;$ squared effect: $\left.\beta_{\mathrm{sq}}=-.02, p<.10\right)$. Not 
surprisingly, these retailers (Albert Heijn and Delhaize) have the largest standard PL assortment proliferation (see Table 1). For these retailers, at first, the probability of a premium PL listing increases with the extent of standard PL SKU proliferation, as it signals a retailer's commitment to his PLs in that category. In these categories, a retailer tries to address consumers' diverse tastes and needs, and introducing a premium PL fits this strategy. At very high levels of standard PL SKU proliferation, however, the retailers become aware of the "crowding effect" (Srinivasan et al. 2004, p. 626) and avoid overextending their PL assortment with too many PL variants to not risk PL fatigue. Using the aforementioned estimates, the switching points $\left[-\beta_{\operatorname{lin}} /\left(2 * \beta_{\mathrm{sq}}\right)\right]$ are situated at around 143 and 119, for Albert Heijn and Delhaize, respectively. The switching points fall well within the range of the data for Albert Heijn and Delhaize (we observe a maximum proliferation of 182 for Albert Heijn and 213 for Delhaize), whereas the other retailers only start to approach these maximum numbers (maximum proliferation equals 117 for Jumbo, 131 for Plus, 107 for Super de Boer, and 122 for Carrefour).

--- Insert Table 2 about here ---

\section{Findings specific to premium PLs: the role of their positioning}

Novel generalizations related to the distinct price positioning of premium PLs

Premium PLs are positioned to be higher in price than standard PLs. As such, several variables that have been studied in the standard PL literature may have a different effect. A category's NB price premium did not have a significant effect $(\bar{\beta}=-.13 ; \mathrm{Z}=-.16, p>.10)$. As such, no support was found for H4. For NB price-promotion intensity, we studied deal frequency and depth. Somewhat surprisingly, we found a significant positive effect of NB deal frequency 
for one of the six retailers (two-sided $p=.02$ ). Moreover, also for the other five retailers the effect of NB deal frequency goes into the same direction. The collective evidence, as reflected in the meta-analysis, results in a highly significant positive effect of NB deal frequency on retailers' proneness to introduce a premium PL in the category $(\bar{\beta}=1.18 ; \mathrm{Z}=2.87, p<.01)$. In these heavily-promoted categories, consumers are generally less loyal to (national) brands (Kumar and Steenkamp 2007), which may signal market opportunities for premium PLs. Indeed, the frequent use of price cuts by NBs in those categories can be seen as evidence of a sufficiently large switching segment that is not hard-core loyal to any of the NBs (see Sethuraman and Raju 2012, p. 329 for a similar reasoning), and that therefore could be lured to the premium PL. Retailers' premium PL introduction decision does not seem to be affected by NB deal depth as the Rosenthal test does not reveal a significant effect $(\bar{\beta}=.22 ; \mathrm{Z}=.37, p>.10)$. Overall, we cannot confirm H5. For interpurchase cycle, we observe a similar pattern for all six retailers. The higher the interpurchase time in the category, the higher the probability that retailers list a premium PL

$(\bar{\beta}=.02 ; \mathrm{Z}=3.76, p<.01)$. As such, we find support for H6. In line with the idea that categories with a shorter interpurchase cycle are characterized by higher price sensitivity, retailers avoid introducing premium PLs in these categories. Whereas standard PLs are well represented in low interpurchase-cycle categories, we find that premium PLs are typically introduced in categories defined as "variety enhancers" or "fill-ins" by Fader and Lodish (1990) and Dhar, Hoch, and Kumar (2001). These "variety enhancing" or "fill-in" categories correspond to the premium PLs' image among industry participants of being exclusive products for special occasions (de Jong 2007). In a similar vein, we find that premium PLs are more likely to be offered in categories in which consumers appreciate more variety $(\bar{\beta}=.51 ; Z=2.94, p<.01)$, which supports H7. 
Novel generalizations related to the distinct quality and imagery positioning of premium PLs Whereas standard PLs are more successful in categories characterized by lower functional and social risk (Steenkamp and Geyskens 2014), premium PLs are primarily introduced in categories characterized by higher functional risk $(\bar{\beta}=.37 ; \mathrm{Z}=1.40, p<.10)$ but lower social risk $(\bar{\beta}=-1.21 ; \mathrm{Z}=-2.33, p<.01)$, confirming $\mathrm{H} 8$ and $\mathrm{H} 9$. As premium PLs are positioned at the top end of the quality spectrum, retail managers are confident that they will be able to compete with NBs on functional risk. However, NBs still excel on brand imagery and retailers refrain from introducing premium PLs in categories where purchases are closely tied to the consumer's self-image, as instilling brand imagery takes much longer to establish.

\section{Findings that could generalize from standard PLs to premium PLS}

Prior generalizations related to the category's potential

For category size, growth, and penetration we expected a positive effect, as evidenced in the existing literature on standard PLs and new product introductions. While we do not find evidence that this effect generalizes to premium PL introduction decisions for category size $(\bar{\beta}=.00 ; \mathrm{Z}=$ $-.12, p>.10$ ), we do find evidence for the expected positive effect of category growth through

the meta-analytic test $(\bar{\beta}=.23 ; \mathrm{Z}=1.87, p<.05)$. However, we do not find that a premium PL is more likely to be introduced in categories with higher penetration levels $(\bar{\beta}=-3.21 ; Z=-1.14$, $p>$.10). Finally, for all four retailers, we find a highly significant effect of the pioneer's 
signaling behavior as reflected by both the meta-analytic findings $(\bar{\beta}=1.65 ; \mathrm{Z}=8.29, p<.01)$ and the individual effects (Jumbo: $\beta_{15}=1.76, p<.01$; Plus: $\beta_{15}=2.29, p<.01$; Super de Boer: $\beta_{15}=1.99, p<.01$; Delhaize: $\left.\beta_{15}=.73, p<.05\right)$. Actions of the premium PL pioneer are clearly seen as a signal of market potential, which increases the retailer's propensity to also introduce a premium PL in that category.

\section{Prior generalizations related to the extant NB competitive setting}

Although for all six retailers the coefficient for NB concentration shows the same sign, the meta-analytic method of added Z's results in an insignificant effect $(\bar{\beta}=.35 ; Z=1.52, p>.10)$. Interestingly, and consistent with our expectations, we find that the effect of NB proliferation follows an inverted U-shape (linear effect: $\bar{\beta}_{\text {lin }}=.13 ; \mathrm{Z}=4.82, p<.01$; squared effect: $\bar{\beta}_{\mathrm{sq}}=$ $-.00 ; \mathrm{Z}=-3.15, p<.01)$. Finally, for two of the six retailers, we find significant support for the expected negative effect of advertising. For three other cases, the effects are of the same negative sign, but do not reach statistical significance. Combining this evidence across all six retailers, we find that higher NB advertising lowers the probability that retailers introduce a premium PL in the category $(\bar{\beta}=-.44 ; \mathrm{Z}=-2.56, p<.01)$, which is consistent with our expectations and existing research on standard PLs. As it did with the standard variants, heavy NB advertising also keeps premium PLs at bay.

Finally, the effect of the presence of an economy PL in the category on the probability of a premium PL introduction is insignificant and positive for Albert Heijn $\left(\beta_{20}=.10, p>.10\right)$, for Super de Boer $\left(\beta_{20}=.66, p>.10\right)$, Carrefour $\left(\beta_{20}=.60, p>.10\right)$, and Delhaize $\left(\beta_{20}=1.36\right.$, $p>.10)$, but negative for Jumbo $\left(\beta_{20}=-1.14, p>.10\right)$. Also meta-analytically, no significant 
effect is found $(\bar{\beta}=.32 ; Z=1.33, p>.10)$.

\section{Normative implications}

Our empirical regularities are largely consistent with theory-based expectations, which suggests that there is a considerable amount of rationality in these retailers' decision making (Steenkamp et al. 2005). In line with the Darwinian economics line of thinking (see, e.g., Anderson 1988), this also suggests the value of looking at the decision rules of prior entrants to compensate for one's own limited experience. However, to more formally investigate whether it pays to adhere to this "combined industry wisdom," we link the premium PLs' post-introduction performance with our model-based prescriptions. Following Brouthers (2002), ${ }^{15}$ we define a fit dummy variable to indicate whether the observed introductions are also predicted by our model in Equation (1).

As a performance metric, we use the premium PL's market share $\left(\mathrm{PL}_{-} \mathrm{MS}_{\mathrm{c}}\right)$ in the first calendar year following its introduction. This one-year focus is in line with Gielens and Steenkamp (2007), and is consistent with the view of industry analysts who consider the firstyear performance of innovations crucial in the CPG industry (Ernst\&Young/ACNielsen 2000). We consider the post-introduction performance of 335 introductions (rather than the 339 reported in Table 1), as we exclude the four Super de Boer observations introduced in 2009, in light of the chain's take-over in 2010. To ensure the range constraint of the market-share metric, we use a logistic transformation, and regress $\ln \left[\mathrm{PL} \_\mathrm{MS}_{\mathrm{ct}+1} /\left(1-\mathrm{PL} \_\mathrm{MS}_{\mathrm{ct}+1}\right)\right]$ on the fit dummy, while controlling for all significant drivers from the first-stage estimation, as well as retailer- and year-

\footnotetext{
${ }^{15}$ A similar approach was also used in Gielens and Dekimpe (2007).
} 
specific fixed effects. As before, robust cluster error-term estimation is used to allow for the potential error correlation among observations within the same broad product group. Importantly, we find that premium PLs that were introduced in a category predicted by our model obtain a significantly better performance in terms of both volume $(\beta=.99, p<.05$, one-sided $)$ and value $(\beta=.92, p<.05$, one-sided $)$ share than premium PL introductions not predicted by our framework, supporting the normative value of our model.

\section{Discussion}

Although standard PLs have been investigated extensively, research on premium PLs is still scarce. Against this backdrop, we theorized and tested how various category characteristics affect retailers' proneness to introduce a premium PL variant in a category next to their standard PL, using data across approximately 150 categories carried by six retailers from two different countries.

While some of the earlier insights from the standard PL or new product literature remain valid (such as the role of category growth, pioneer signaling behavior, NB proliferation, and NB advertising) for the new reality of premium PL additions, new variables had to be considered, while other insights needed to be adjusted to better reflect premium PLs' very different positioning (see Table 3 for an overview).

When deciding to introduce a standard PL, retailers only had to take into account the extant NB competitive setting whereas retailers' inclination to introduce a premium PL also depends on the extant PL competitive setting. This new competitive setting has brought novel drivers to the forefront. Most notably, the set of incumbent products has been extended, and no longer consists 
only of NBs. Indeed, the composition (proliferation of the standard PL tier) and success (share) of the current PL offering play an important role when retailers decide in what categories to take their PL portfolio upmarket. Retailers not only take the intrinsic appeal of PLs in a particular category into account, they also carefully consider PL fatigue that premium-tier extensions may bring along and avoid overcrowding the category.

Given that the positioning of premium PLs is very different from the positioning of standard PLs, the role of several factors had to be reconsidered. Two notable examples are the impact of purchase frequency and functional risk. In contrast to standard PLs, retailers introduce their premium PL versions more in special-occasion categories (which typically have a longer interpurchase time). Also, while higher functional risk was found to deter standard PL entry, it enhances the likelihood that a premium variant is introduced.

--- Insert Table 3 about here ---

Our results offer important managerial insights. Given that in many countries and for many retailers, premium PLs are still a fairly recent phenomenon, our findings summarize the already available "collective wisdom" of the industry. Our subsequent analysis on the model's normative implications shows that retailers who are expected to launch a premium PL soon, who have just very recently done so (as U.K.-based Wilkinson or South African Pick n Pay), or who wish to expand their existing premium PL portfolio (like Tesco Finest and CVS Gold Emblem Select), can indeed benefit from this wisdom to reduce the uncertainty associated with such a strategic, yet unfamiliar, move. As European retailers are at the forefront of most PL developments, examining what they have done and are doing offers clues to what is in store for the rest of the world (The Nielsen Company 2011, p. 6).

NB manufacturers can benefit from these insights as well. First, they should be aware that 
the "battle-field" has shifted. While standard PLs were introduced first (and were most successful) in high-penetration (i.e., staple and variety-enhancing) categories, premium PLs are more likely to be found in low purchase-frequency (i.e., variety-enhancing and fill-in) categories. Brand managers in those categories may have less experience on how to successfully fight PL brands: as the standard variety was introduced in those categories at a later point in time, the accumulated experience on how to adequately deal with them will be smaller (Steenkamp et al. 2010). Moreover, the share of the standard PLs in these categories tends to be smaller, making them historically less of a threat. A similar reasoning holds for NBs in categories with higher functional risk in which standard PLs could be kept at bay because of their lower quality, but where premium PLs are a clear threat.

Second, given the clear imitation effect among retailers, brand managers faced with the arrival of a first premium PL entrant should brace themselves against the arrival of other such high-quality PL variants. Moreover, the emergence of various premium PLs from a diverse set of retailers may help their legitimation with customers in that category (Gielens and Dekimpe 2007; Koçak and Özcan 2013), and facilitate their further penetration.

Finally, managers can learn what strategies they can use pro-actively to make their category less attractive for premium PL entry. First, even though objective quality may no longer be a differentiating factor, advertising (with its emphasis on less tangible differentiating aspects, i.e., imagery) continues to be a deterrent to further PL entry. Another lever that can still be played is the social risk in a category. NBs can try to increase the social risk in a category by forging a stronger bond between consumers and their brands (Fournier 1998). Also, many brand managers still resort to frequent price cuts in an attempt to curb PL growth. Such a practice has already been questioned when dealing with standard variants (see, e.g., Steenkamp and Dekimpe 1997), 
but it may inadvertently open the door for the upmarket version as well. As "the rise of the premium PL will further fasten the commoditization of NBs" (FSIN 2009), brand managers should try instead to convey to consumers that NBs are still superior to deter premium PL entry. In case retailers enter anyway with an upmarket version, this same strategy may continue to help the highest-quality NBs. Indeed, when a NB is perceived to be the most similar, but still superior, option to a premium PL, the latter's presence can actually increase the choice share of these NBs (Geyskens et al. 2010).

\section{Limitations and further research}

Our research has several limitations that offer interesting avenues for future research. From a modelling point of view, we did not explicitly correct for unobserved heterogeneity beyond our flexible specification of the baseline hazard (which picks up both individual-level time dependence and unobserved heterogeneity; see Vanhuele et al. 1995 for an in-depth discussion). Still, the use of an additional mixing distribution on the baseline hazard could further reduce any remaining sorting effect. ${ }^{16}$ Also, we did not capture the start of the introduction history for three retailers, resulting in a left-censoring issue. Specifically, at the start of our analysis window, there were already 5 (Albert Heijn), 19 (Carrefour), and 3 (Delhaize) categories with a premium PL. To account for that, these categories were not included in our starting set of categories at risk. For Albert Heijn and Delhaize, this number is very small compared to the number of categories still considered (1978 and 187; see Table 1), which limits the potential impact. Given the somewhat higher number of instances for Carrefour, we also computed the meta-analytic results

\footnotetext{
${ }^{16}$ However, this should primarily affect the time-varying intercepts (which are not the focus of our subsequent metaanalysis), rather than the focal slope coefficients in Equation (1).
} 
without this retailer, and found the results to be robust. ${ }^{17}$ Finally, one could (once a longer window of observations becomes available) extend the hazard specification of Equation (1) to the split-hazard approach advocated in Dekimpe, Parker, and Sarvary (2000) and Dekimpe et al. (1998) to formally test what fraction of categories will eventually witness a premium PL introduction.

More substantively, our sample was limited to retailers in a grocery setting. However, strong retail chains that emphasize own brand labels are also present in other sectors, such as apparel, household appliances, and consumer electronics. It would be interesting to study whether the same factors drive a retailer's decision to add premium PL variants in those environments.

In addition, we studied premium PLs at six leading European supermarkets. Still, it would be interesting to explore whether our findings also generalize to other formats as, for example, (hard) discounters. Germany’s leading discounter Aldi, for example, recently introduced a premium PL line (PlanetRetail 2008b). Future research could investigate whether they were guided by the same principles in their selection of categories. Relatedly, Western Europe is the most mature PL market in the world. It would be interesting to see whether the same principles hold in other markets where PLs are still in the growth stage of their life cycle (as in many emerging markets), and/or in markets where standard PLs have a lower quality perception (as in the U.S.). It may be worthwhile to investigate the extent to which this quality differential increases the hurdle for premium PL introductions, or whether it offers instead more differentiation opportunities.

The recent economic downturn has driven many consumers towards PLs (see, e.g., Lamey et al. 2012). However, consumers increasingly feel a "frugal fatigue", and long to indulge themselves with something more "expensive, or at least frivolously indulgent" (Store Brand

\footnotetext{
${ }^{17}$ Detailed results are available from the first author upon request.
} 
Decisions 2012). Responding to this desire, Spar Austria's CEO Gerhard Drexel, when launching the SPAR PREMIUM tier, emphasized their objective to "democratize luxury" (Press release of October 7, 2010) by offering premium quality at affordable prices, allowing their customers to "indulge in something special." 18 This evolution could (even though more formal testing is needed to substantiate this claim) help explain why the premium tier has been the fastest-growing PL segment. Given that it also results in higher retailer margins, it should come as no surprise that grocery retailers across the board announce plans to add premium PLs to their PL portfolio (Packaged Facts 2012). We hope that the empirical generalizations derived from six European retailers that are at the forefront of this evolution will prove useful to other retailers, and encourage further research on this new trend.

\footnotetext{
${ }^{18}$ To underscore this argument, the launch was backed by a large-scale TV campaign featuring Pierce Brosnan in typical James Bond style and a four-star restaurant chef.
} 


\section{Acknowledgements}

We acknowledge AiMark for providing access to the GfK consumer panel data. We are indebted to the Netherlands Organization for Scientific Research (NWO) for financial assistance, and thank Barbara Deleersnyder, Karen Gedenk, Els Gijsbrechts, Koen Pauwels, and Raj Sethuraman for insightful comments on an earlier draft. 


\section{References}

Aaker, David A. and Kevin Lane Keller (1990), “Consumer Evaluations of Brand Extensions,” Journal of Marketing, 54 (1), 27-41.

Aaker, Jennifer Lynn, Verónica Benet-Martínez and Jordi Garolera (2001), “Consumption Symbols as Carriers of Culture: A Study of Japanese and Spanish Brand Personality Constructs," Journal of Personality and Social Psychology, 81 (3), 492-508.

Ailawadi, Kusum L. and Bari Harlam (2004), “An Empirical Analysis of the Determinants of Retail Margins: The Role of Store-Brand Share,” Journal of Marketing, 68 (1), 147-165.

---, Donald R. Lehmann and Scott A. Neslin (2003), "Revenue Premium as an Outcome Measure of Brand Equity," Journal of Marketing, 67 (4), 1-17.

---, Koen Pauwels and Jan-Benedict E.M. Steenkamp (2008), "Private-Label Use and Store Loyalty," Journal of Marketing, 72 (6), 19-30.

Alexander, David L., John G. Lynch Jr. and Qing Wang (2008), “As Time Goes By: Do Cold Feet Follow Warm Intentions for Really New Versus Incrementally New Products?” Journal of Marketing Research, 45 (3), 307-319.

Anderson, Erin (1988), "Strategic Implications of Darwinian Economics for Selling Efficiency and Choice of Integrated or Independent Sales Forces,” Management Science, 34 (5), 599618.

Barwise, Patrick (1995), “Good Empirical Generalizations,” Marketing Science, 14 (3), 29-35.

Baumgartner, Hans and Jan-Benedict E.M. Steenkamp (1996), "Exploratory Consumer Buying Behavior: Conceptualization and Measurement," International Journal of Research in Marketing, 13 (2), 121-137.

Bazoche, Pascale, Eric Giraud-Héraud and Louis-Georges Soler (2005), "Premium Private Labels, Supply Contracts, Market Segmentation, and Spot Prices,” Journal of Agricultural \& Food Industrial Organization, 3 (1), 1-30.

Boulding, William, Eunkyu Lee and Richard Staelin (1994), "Mastering the Mix: Do Advertising, Promotion and Sales Force Activities Lead to Differentiation?” Journal of Marketing Research, 31 (2), 159-172.

Brouthers, Keith D. (2002), "Institutional, Cultural and Transaction Cost Influences on Entry 
Mode Choice and Performance," Journal of International Business Studies, 33 (2), 203-221. Carow, Kenneth, Randall Heron and Todd Saxton (2004), "Do Early Birds Get the Returns? An Empirical Investigation of Early-Mover Advantages in Acquisitions," Strategic Management Journal, 25 (6), 563-585.

Cleeren, Kathleen, Harald J. van Heerde and Marnik G. Dekimpe (2013), "Rising from the Ashes: How Brands and Categories Can Overcome Product-Harm Crises," Journal of Marketing, 77 (2), 58-77.

Cohen, Jacob, Patricia Cohen, Stephen G. West and Leona S. Aiken (2003), Applied Multiple Regression/Correlation Analysis for the Behavioral Sciences. Mahwah, NJ: Lawrence Erlbaum Associates.

de Jong, Koen A.M. (2007), Private Labels in Europe - Trends and Challenges For Retailers and Manufacturers. Vught, the Netherlands: International Private Label Consult.

--- (2011), Private Label Uncovered - Taking Retailer Brands to the Next Level. Vught, the Netherlands: International Private Label Consult.

Dekimpe, Marnik G., Katrijn Gielens, Jagmohan Raju and Jacquelyn S. Thomas (2011), "Strategic Assortment Decisions in Information-Intensive and Turbulent Environments," Journal of Retailing, 87 (1), 17-28.

---, Philip M. Parker and Miklos Sarvary (2000), “Globalization: Modeling Technology Adoption Timing Across Countries," Technological Forecasting and Social Change, 63 (1), 25-42.

---, Linda M. Van de Gucht, Dominique M. Hanssens and Keiko I. Powers (1998), “Long-Run Abstinence After Narcotics Abuse: What Are the Odds?” Management Science, 44 (11-1), 1478-1492.

Deleersnyder, Barbara, Marnik G. Dekimpe, Jan-Benedict E.M. Steenkamp and Oliver Koll (2007), "Win-Win Strategies at Discount Stores," Journal of Retailing and Consumer Services, 14 (5), 309-318.

---, ---, --- and Peter S.H. Leeflang (2009), “The Role of National Culture in Advertising's Sensitivity to Business Cycles: An Investigation Across Continents," Journal of Marketing Research, 46 (5), 623-636.

Dhar, Sanjay K. and Stephen J. Hoch (1997), "Why Store Brand Penetration Varies by Retailer," Marketing Science, 16 (3), 208-227. 
---, --- and Nanda Kumar (2001), "Effective Category Management Depends on the Role of the Category," Journal of Retailing, 77 (2), 165-184.

Distrifood (2010), Klant Vindt Kerstaanbod al Vroeg, (accessed December 9, 2013), [http://www.fws.nl/nieuws/frisdranken/klant-vindt-kerstaanbod-al-vroeg].

Dobson, Paul W. and Ratula Chakraborty (2009), "Private Labels and Branded Goods: Consumers' 'Horrors' and 'Heroes',' in Private Labels, Brands, and Competition Policy, Ariel Ezrachi and Ulf Bernitz, eds. New York: Oxford University Press, 99-124.

Erdem, Tulin, Ying Zhao and Ana Valenzuela (2004), "Performance of Store Brands: A Cross-Country Analysis of Consumer Store Brand Preferences, Perceptions and Risk," Journal of Marketing Research, 41 (1), 86-115.

Ernst \& Young/ACNielsen (2000), New Product Introduction, Successful Innovation/Failure: A Fragile Boundary. Paris: Ernst \& Young Global Client Consulting.

Fader, Peter S. and Leonard M. Lodish (1990), “A Cross-Category Analysis of Category Structure and Promotional Activity for Grocery Products," Journal of Marketing, 54 (4), $52-$ 65.

Fournier, Susan (1998), "Consumers and Their Brands: Developing Relationship Theory in Consumer Research,” Journal of Consumer Research, 24 (4), 343-353.

FSIN (2009), Metamorfose Merkenlandschap, (accessed December 9, 2013), [http://www.evmi.nl/nieuws/marketing-sales/7157/metamorfose-merkenlandschap.html]. Geletkanycz, Marta A. and Donald C. Hambrick (1997), “The External Ties of Top Executives: Implications for Strategic Choice and Performance,” Administrative Science Quarterly, 42 (4), 654-681.

Geyskens, Inge, Katrijn Gielens and Els Gijsbrechts (2010), "Proliferating Private-Label

Portfolios: How Introducing Economy and Premium Private Labels Influences Brand Choice," Journal of Marketing Research, 47 (5), 791-807.

Gielens, Katrijn (2012), “New Products: The Antidote to Private Label Growth?” Journal of Marketing Research, 49 (3), 408-423.

--- and Marnik G. Dekimpe (2007), “The Entry Strategies of Retail Firms Into Transition Economies," Journal of Marketing, 71 (2), 196-212.

--- and Jan-Benedict E.M. Steenkamp (2007), "Drivers of Consumer Acceptance of New Packaged Goods: An Investigation across Products and Countries," International Journal of 
Research in Marketing, 24 (2), 97-112.

Greene, William (2000), Econometric Analysis. Upper Saddle River, NJ: Prentice Hall.

Heinze, Georg (1999), The Application of Firth's Procedure to Cox and Logistic Regression, Technical Report 10/1999, University of Vienna.

Henard, David H. and David M. Szymanski (2001), "Why Some New Products Are More Successful Than Others," Journal of Marketing Research, 38 (3), 362-375.

Hoch, Stephen J. and Shumeet Banerji (1993), “When Do Private Labels Succeed?" Sloan Management Review, 34 (4), 57-68.

IGD (2006), European Private Label Growth: Strategic Responses for Suppliers and Retailers. Watford: IGD.

IRI (2009), Times \& Trends Special Edition: U.S. \& Europe Private Label 2009, (accessed December 9, 2013), [http://www.iriworldwide.com/portals/0/articlePdfs/T_T-SeptOct-2009Private-Label-US_Europe.pdf].

Judge, George G., R. Carter Hill, William E. Griffiths, Helmut Lütkepohl and Tsoung-Chao Lee (1988), Introduction to the Theory and Practice of Econometrics. New York: John Wiley \& Sons.

Keller, Kevin Lane (1998), Strategic Brand Management: Building, Measuring and Managing Brand Equity. Upper Saddle River, NJ: Prentice Hall.

Koçak, Özgecan and Serden Özcan (2013), “How Does Rivals’ Presence Affect Firms’ Decision to Enter New Markets: Economic and Sociological Explanations," Management Science, 59 (11), 2586-2603.

Kumar, Nirmalya and Jan-Benedict E.M. Steenkamp (2007), Private Label Strategy. Cambridge, MA: Harvard Business School Press.

Lamey, Lien, Barbara Deleersnyder, Jan-Benedict E.M. Steenkamp and Marnik G. Dekimpe (2012), "The Effect of Business Cycle Fluctuations on Private-Label Share: What Has Marketing Conduct Got to Do with It?” Journal of Marketing, 76 (1), 1-19.

Laurent, Gilles and Jean-Noël Kapferer (1985), "Measuring Consumer Involvement Profiles," Journal of Marketing Research, 22 (1), 41-53.

Martos-Partal, Mercedes and Óscar González-Benito (2011), "Store Brand and Store Loyalty:

The Moderating Role of Store Brand Positioning," Marketing Letters, 22 (3), 297-313. Mela, Carl F., Sunil Gupta and Donald R. Lehmann (1997), "The Long-Term Impact of 
Promotion and Advertising on Consumer Brand Choice," Journal of Marketing Research, 34 (2), 248-261.

Mittelstaedt, Robert A., Sanford L. Grossbart, William W. Curtis and Stephen P. Devere (1976), “Optimal Stimulation Level and the Adoption Decision Process," Journal of Consumer Research, 3 (2), 84-94.

Mizik, Nathalie and Robert Jacobson (2009), "Valuing Branded Businesses," Journal of Marketing, 73 (6), 137-153.

Morrison, Donald G. (1969), “On the Interpretation of Discriminant Analysis," Journal of Marketing Research, 6 (2), 156-163.

Nijs, Vincent R., Marnik G. Dekimpe, Jan-Benedict E.M. Steenkamp and Dominique M. Hanssens (2001), “The Category-Demand Effects of Price Promotions," Marketing Science, $20(1), 1-22$.

Packaged Facts (2012), Premium Private Label Groceries Trump Frugal Fatigue, (accessed December 9, 2013), [http://www.packagedfacts.com/about/release.asp?id=3036].

Palmeira, Mauricio M. and Dominic Thomas (2011), “Two-Tier Store Brands: The Benefic Impact of a Value Brand on Perceptions of a Premium Brand," Journal of Retailing, 87 (4), 540-548.

Pauwels, Koen and Shuba Srinivasan (2009), "Pricing of National Brands versus Store Brands: Market Power Components, Findings and Research Opportunities," in Handbook of Pricing Research in Marketing, Vithala R. Rao, ed. Northampton, MA: Edward Elgar Publishing, 258-282.

Pierce, John. J., Sean Ryan and Peter Berlinksi (2002), Premium Private Label Stars in All

Channels of Trade, Large and Small Retailers, (accessed December 9, 2013),

[http://www.plstorebrands.com/plmag-article-premium_private_label_stars_in_all_ channels_of_trade_large_and_small_retailers-4089.html].

PlanetRetail (2008a), Grocery Retailing in U.S.A. London: Planet Retail.

--- (2008b), Discounters vs. Convenience: The Turf Wars. London: Planet Retail.

Raju, Jagmohan S., Raj Sethuraman and Sanjay K. Dhar (1995), “The Introduction and Performance of Store Brands,” Management Science, 41 (6), 957-978.

Rangan, V. Kasturi and Marie Bell (2003), H-E-B Own Brands. Boston, MA: Harvard Business School Publishing. 
Rao, Ram C., Ramesh V. Arjunji and B.P.S. Murthi (1995), "Game Theory and Empirical Generalizations Concerning Competitive Promotions," Marketing Science, 14 (3), G89-G100. Rao, Vithala R. and Edward W. McLaughlin (1989), "Modeling the Decision to Add New Products by Channel Intermediaries," Journal of Marketing, 53 (1), 80-88.

Reibstein, David J. and Paul W. Farris (1995), "Market Share and Distribution: A Generalization, a Speculation, and Some Implications,” Marketing Science, 14 (3), 190-202.

Robinson, William T. (1988), “Marketing Mix Reactions to Entry,” Marketing Science, 7 (4), 368-385.

Rosenthal, Robert (1991), Meta-Analytic Procedures for Social Research. Newbury Park: Sage. Sayman, Serdar and Jagmohan S. Raju (2004), "How Category Characteristics Affect the Number of Store Brands Offered by the Retailer: A Model and Empirical Analysis," Journal of Retailing, 80 (4), 279-287.

--- and --- (2007), "Store Brands: From Back to the Future," in Review of Marketing Research, Naresh K. Malhotra, ed. Emerald Group Publishing Limited, 132-151.

Scott-Morton, Fiona and Florian Zettelmeyer (2004), "The Strategic Positioning of Store Brands in Retailer-Manufacturer Negotiations," Review of Industrial Organization, 24 (2), 161-194. Sethuraman, Raj (1992), “The Effect of Marketplace Factors on Private Label Penetration in Grocery Products,” Report No. 92-128. Cambridge, MA: Marketing Science Institute Working Paper Series.

--- (2009), “Assessing the External Validity of Analytical Results from National Brand and Store Brand Competition Models,” Marketing Science, 28 (4), 759-781.

--- and Katrijn Gielens (2013), "From Empirical Generalizations to Empirical Stories on The Determinants of Store Brand Performance," working paper.

--- and Jagmohan S. Raju (2012), "Private Label Strategies - Myths and Realities," in Handbook of Marketing Strategy, Venkatesh Shankar and Gregory S. Carpenter, eds. Northampton, MA: Edward Elgar Publishing, 318-335.

Singer, Judith D. and John B. Willett (2003), Applied Longitudinal Data Analysis: Modeling Change and Event Occurrence. New York: Oxford University Press.

Srinivasan, Shuba, Koen Pauwels, Dominique M. Hanssens and Marnik G. Dekimpe (2004), "Do Promotions Benefit Manufacturers, Retailers, or Both?” Management Science, 50 (5), 617629. 
Sriram, S., Subramanian Balachander and Manohar U. Kalwani (2007), "Monitoring the Dynamics of Brand Equity Using Store-Level Data,” Journal of Marketing, 71 (2), 61-78.

Steenkamp, Jan-Benedict E.M. and Marnik G. Dekimpe (1997), "The Increasing Power of Store Brands: Building Loyalty and Market Share,” Long Range Planning, 30 (6), 917-930.

---, Inge Geyskens, Katrijn Gielens and Oliver Koll (2004), Fighting Private Label - Growth Drivers, Brand Defence Strategies, and. Market Opportunities. Business Insights in association with AiMark and Europanel.

--- and Inge Geyskens (2014), "Manufacturer and Retailer Strategies to Impact Store Brand Share: Global Integration, Local Adaptation, and Worldwide Learning," Marketing Science, Forthcoming.

---, Harald J. van Heerde and Inge Geyskens (2010), "What Makes Consumers Willing to Pay a Price Premium for National Brands over Private Labels?" Journal of Marketing Research, 47 (6), 1011-1024.

---, Vincent Nijs, Dominique M. Hanssens and Marnik G. Dekimpe (2005), “Competitive Reactions to Advertising and Promotion Attacks," Marketing Science, 24 (1), 35-54.

Stepanova, Maria and Lyn Thomas (2002), "Survival Analysis Methods for Personal Loan Data," Operations Research, 50 (2), 277-289.

Store Brand Decisions (2012), Premium Private Label Groceries Trump Frugal Fatigue, (accessed December 9, 2013), [http://www.storebrandsdecisions.com/news/2012/10/30/ premium-private-label-groceries-trump-frugal-fatigue].

--- (2013), Tesco Relaunches Finest, (accessed December 9, 2013),

[http://www.storebrandsdecisions.com/news/2013/10/08/tesco-relaunches-finest-]. SymphonyIRI (2011), Retail Private Label Brands in Europe: Current and Emerging Trends. Special Report.

Szymanowski, Maciej and Els Gijsbrechts (2012), "Consumption Based Cross-Brand Learning: Are Private Labels Really Private?” Journal of Marketing Research, 49 (2), 231-246. ter Braak, Anne, Marnik G. Dekimpe and Inge Geyskens (2013), "Retailer Private-Label Margins: The Role of Supplier and Quality-Tier Differentiation," Journal of Marketing, 77 (4), 86-103.

Thain, Greg and John Bradley (2012), Store Wars: The Worldwide Battle for Mindspace and Shelfspace, Online and In-Store. United Kingdom: John Wiley \& Sons. 
The Nielsen Company (2011), The Rise of the Value-Conscious Shopper: A Nielsen Global Private Label Report, (accessed December 9, 2013), [http://hk.nielsen.com/documents/PrivateLabelGlobalReport.pdf].

van Heerde, Harald J., Maarten J. Gijsenberg, Marnik G. Dekimpe and Jan-Benedict E.M. Steenkamp (2013), "Price and Advertising Effectiveness over the Business Cycle," Journal of Marketing Research, 50 (2), 177-193.

Vanhuele, Marc, Marnik G. Dekimpe, Sunil Sharma and Donald G. Morrison (1995), "Probability Models for Duration: The Data Don't Tell the Whole Story," Organizational Behavior and Human Decision Processes, 61 (1), 1-13.

van Trijp, Hans C.M., Wayne D. Hoyer and J. Jeffrey Inman (1996), "Why Switch? Product Category-Level Explanations for True Variety-Seeking Behavior," Journal of Marketing Research, 33 (3), 281-292.

Wildner, Raimund (2013), "Success Factors in Brand Communication 2.0," paper presented at the 2013 AiMark/Gfk Summit, Paris.

Woltman Elpers, Josephine L.C.M., Michel Wedel and Rik G.M. Pieters (2003), "Why Do Consumers Stop Viewing Television Commercials? Two Experiments on the Influence of Moment-to-Moment Entertainment and Information Value," Journal of Marketing Research, 40 (4), 437-453.

Wooldridge, Jeffrey M. (2009), Introductory Econometrics; A Modern Approach. Mason, OH: South-Western College Publication Cengage Learning. 
TABLE 1

DESCRIPTIVES

\begin{tabular}{|c|c|c|c|c|c|c|}
\hline & $\begin{array}{l}\text { Albert } \\
\text { Heijn }\end{array}$ & Jumbo & Plus & $\begin{array}{c}\text { Super } \\
\text { de Boer }\end{array}$ & Carrefour & Delhaize \\
\hline Number of observations & 976 & 629 & 728 & 699 & 615 & 905 \\
\hline Number of categories & 179 & 153 & 142 & 152 & 158 & 187 \\
\hline Number of premium PL introductions & 94 & 56 & 58 & 35 & 72 & 24 \\
\hline \multicolumn{7}{|l|}{ Mean value of } \\
\hline Industry PL share & .47 & .55 & .58 & .53 & .55 & .55 \\
\hline Standard PL share & .48 & .38 & .45 & .42 & .32 & .36 \\
\hline Standard PL proliferation (\# of SKUs/10) & 1.17 & 1.10 & .95 & 1.12 & 1.06 & 1.57 \\
\hline NB price premium & 1.19 & 1.24 & 1.31 & 1.20 & 1.52 & 1.30 \\
\hline NB deal frequency & .21 & .14 & .21 & .20 & .20 & .17 \\
\hline NB deal depth & .19 & .15 & .16 & .18 & .20 & .21 \\
\hline Interpurchase cycle (in days) & 62.63 & 56.52 & 60.18 & 61.92 & 55.43 & 57.38 \\
\hline Need for variety & 3.22 & 3.26 & 3.26 & 3.28 & 3.36 & 3.40 \\
\hline Functional risk & 2.75 & 2.81 & 2.81 & 2.81 & 2.91 & 2.96 \\
\hline Social risk & 2.14 & 2.16 & 2.15 & 2.16 & 2.11 & 2.12 \\
\hline Category size & $€ 807,228$ & $€ 325,504$ & $€ 235,987$ & $€ 300,783$ & $€ 344,369$ & $€ 656,335$ \\
\hline Category growth & 1.08 & 1.24 & 1.11 & .99 & 1.01 & 1.07 \\
\hline Category penetration & .21 & .19 & .17 & .17 & .11 & .14 \\
\hline Pioneer signaling behavior & n.a. & .35 & .32 & .28 & n.a. & .23 \\
\hline NB concentration & .53 & .39 & .44 & .42 & .47 & .51 \\
\hline NB proliferation (\# of SKUs/10) & 3.31 & 4.69 & 3.96 & 4.44 & 4.44 & 4.00 \\
\hline NB advertising & 3.25 & 3.24 & 3.23 & 3.26 & 3.26 & 3.25 \\
\hline
\end{tabular}

Notes. Mean statistics are derived from the category-year dataset. n.a. = not applicable. 
TABLE 2: EMPIRICAL RESULTS

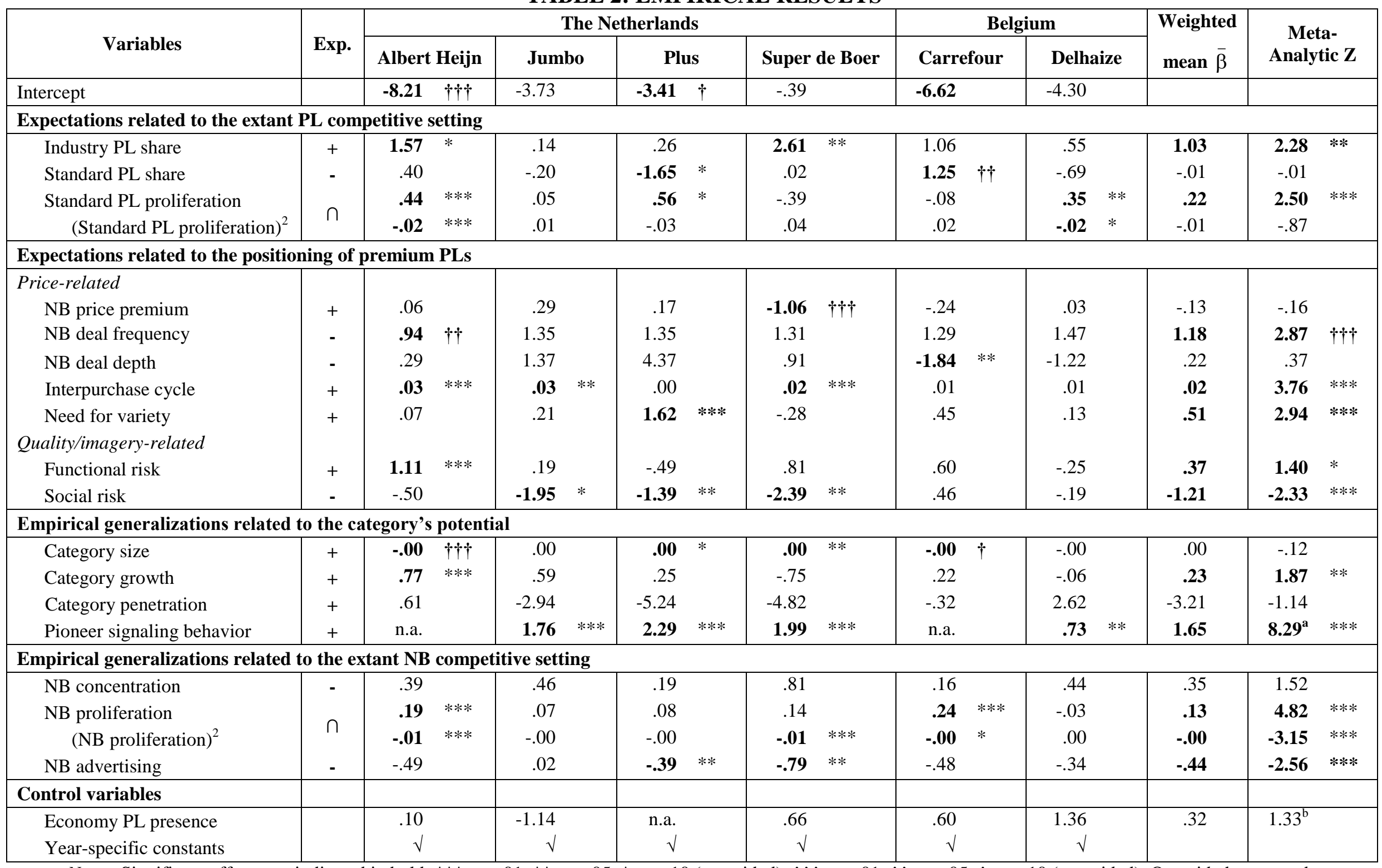

Year-specific constants

for directional hypotheses, two-sided tests otherwise. Weight for $\beta$ is inverse of its standard error, normalized to 1.

${ }^{\mathrm{a}}$ Computed across 4 (rather than 6) retailers. ${ }^{\mathrm{b}}$ Computed across 5 (rather than 6) retailers. 
TABLE 3

STANDARD VS. PREMIUM PL

\begin{tabular}{|c|c|c|c|}
\hline \multirow[b]{2}{*}{ Variable } & \multirow{2}{*}{$\begin{array}{l}\text { Standard PL } \\
\text { Documented } \\
\text { relationship }^{a}\end{array}$} & \multicolumn{2}{|c|}{ Premium PL } \\
\hline & & $\begin{array}{c}\text { Predicted } \\
\text { relationship }\end{array}$ & $\begin{array}{l}\text { Empirical } \\
\text { finding }\end{array}$ \\
\hline \multicolumn{4}{|c|}{ Expectations related to the extant PL competitive setting } \\
\hline Industry PL share & n.a. & + & + \\
\hline Standard PL share & n.a. & - & n.s. \\
\hline Standard PL proliferation & n.a. & $\cap$ & + \\
\hline \multicolumn{4}{|c|}{ Expectations related to the positioning of premium PLs } \\
\hline NB price premium & + & + & n.s. \\
\hline NB price-promotion intensity & $+/-$ & - & + \\
\hline Interpurchase cycle & n.s. & + & + \\
\hline Need for variety & n.a. & + & + \\
\hline Functional risk & - & + & + \\
\hline Social risk & - & - & - \\
\hline \multicolumn{4}{|c|}{ Empirical generalizations related to the category's potential } \\
\hline Category size & + & + & n.s. \\
\hline Category growth & + & + & + \\
\hline Category penetration & + & + & n.s. \\
\hline Pioneer signaling behavior & + & + & + \\
\hline \multicolumn{4}{|c|}{ Empirical generalizations related to the extant NB competitive setting } \\
\hline NB concentration & - & - & n.s. \\
\hline NB proliferation & $\cap$ & $\cap$ & $\cap$ \\
\hline NB advertising & - & - & - \\
\hline
\end{tabular}

Geyskens (2014). Notes: n.a. = not available; n.s. = not significant. 
FIGURE 1

CONCEPTUAL FRAMEWORK

Expectations related to the extant PL competitive setting

- Industry PL share (H1)

- Standard PL share (H2)

- Standard PL proliferation (H3)

Expectations related to the positioning of premium PLs

\section{Price-related}

- NB price premium (H4)

- NB price-promotion intensity (H5)

- Interpurchase cycle (H6)

- Need for variety (H7)

\section{Quality/imagery-related}

- Functional risk (H8)

- Social risk (H9)
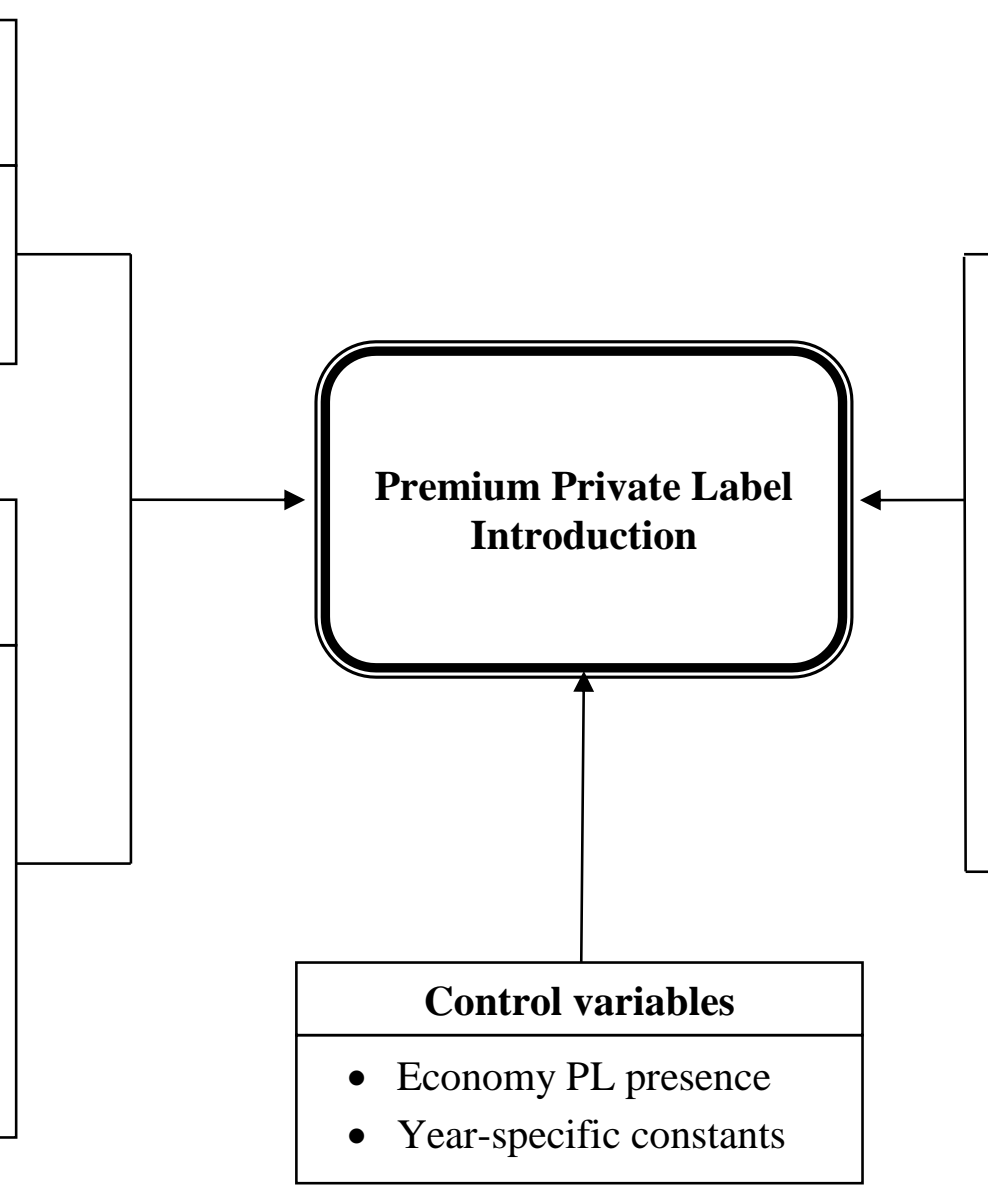

Expectations related to the extant NB competitive setting

- NB concentration

- NB proliferation

- $\quad$ NB advertising

Expectations related to the category's potential

- Category size

- Category growth

- Category penetration

- Pioneer signaling behavior 